Tema: Produtos Metálicos não-ferrosos

\title{
ESTUDO DO EFEITO DO ELEMENTO DE LIGA ZIRCÔNIO SOBRE AS PROPRIEDADES ELETROMECÂNICAS DA LIGA Al-0,05\%Cu-[0,4]\%Fe PARA USO EM TRANSMISSÃO E DISTRIBUIÇÃO DE ENERGIA ELÉTRICA*
}

Resumo

Everaldo Afonso Fernandes ${ }^{1}$ Whellisson da Silva Dias ${ }^{1}$ Mauro Quaresma Lobato ${ }^{1}$ Paulo Cordeiro Machado ${ }^{2}$ José Maria do Vale Quaresma ${ }^{3}$

O estudo do efeito do elemento de liga Zircônio, nos teores 0,15\% e 0,22\%, sobre a liga $\mathrm{AL}-0,05 \% \mathrm{Cu}-[0,35-0,45] \% \mathrm{Fe}$ foi realizado com a finalidade de caracterizar 0 desempenho em cabos e fios para fins de transmissão e distribuição de energia elétrica. Dessa forma, foi adotada sequencia operacional a fim de caracterizar as estruturas apresentadas pelas ligas. O processo de solidificação foi realizado de modo unidirecional horizontal. Posteriormente os lingotes passaram pelos processos mecânicos de usinagem e laminação para obtenção de corpos de prova com quatro distintos diâmetros $(2,7 ; 3,0 ; 3,8 ; 4,0) \mathrm{mm}$ a fim de se ter amostras próximas das bitolas utilizadas nas indústrias de cabos elétricos. Todas as ligas foram caracterizadas termicamente [Análise Térmica], eletromecanicamente por meio do ensaio de tração [LRT] e condutividade elétrica [\%IACS].

Palavras-chave: Zircônio; Análise térmica; Tração; Condutividade elétrica.

\section{STUDY OF THE EFFECT OF ZIRCONIUM ALLOY ELEMENT ON ELECTROMECHANICAL PROPERTIES OF THE ALLOY AI-0.05\%Cu-[0.4]\%Fe FOR USE IN TRANSMITION AND DISTRIBUITION OF ELECTRICAL ENERGY}

\begin{abstract}
The study of the effect of the zirconium alloying element,in the content $0.15 \%$ and $0.22 \%$ on the alloy $\mathrm{Al}-0.05 \mathrm{wt} \% \mathrm{Cu}-[0.35-0.45] \mathrm{wt} \% \mathrm{Fe}$ was performed with the finality to characterize the performance in wires and cables for transmition and distribution of electricity. Thus, operating sequence was adopted to characterize the structures provided by the leagues. Solidification process was performed in horizontal unidirectional mode. Posteriorly the ingots passed by mechanical process machining and lamination for obtaining specimens with four different diameters $(2.7,3.0,3.8$, 4.0) $\mathrm{mm}$ for the purpose of approximate these in the gauges used in electrical cable industries. All alloys were characterized thermally [Thermal Analysis], electromechanically through the tensile test [LRT] and electrical conductivity [\% IACS].
\end{abstract}

Key words: Zirconium; Thermal analysis; Tensile test; Electrical conductivity.

1 Engenheiro Mecânico, Mestrando em Engenharia Mecânica, Universidade Federal do Pará (UFPA), Belém, PA, Brasil.

2 Engenheiro Mecânico, Mestre em Engenharia Mecânica, Doutorando em Engenharia Mecânica, UFPA, Belém, PA, Brasil.

3 Engenheiro Mecânico, Prof. Dr., Engenharia Mecânica, Universidade Federal do Pará, Belém, $P A$, Brasil.

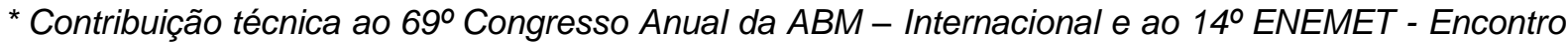
Nacional de Estudantes de Engenharia Metalúrgica, de Materiais e de Minas, 21 a 25 de julho de 2014, São Paulo, SP, Brasil. 


\section{INTRODUÇÃO}

Atualmente o Brasil vem investindo maciçamente em novas usinas produtoras de energia, todo esse investimento se dá devido a grande demanda por esse serviço, para termos uma ideia melhor sobre esse cenário utilizaremos como exemplo alguns dados estatísticos sobre o ano de 2013.

Em novembro de 2013 o consumo de energia elétrica atingiu 47.779 GWh, considerando autoprodução e acrescido das perdas, representando aumento de $5,3 \%$ sobre o mesmo mês de 2012. De forma acumulada nos últimos 12 meses (Dez/12 a Nov/13), o incremento de consumo de energia verificado foi de $3,6 \% \mathrm{em}$ relação a igual período anterior.

O consumo residencial em novembro de 2013 acumulou crescimento de 6,3\% em 12 meses sobre o mesmo período anterior e avançou $4,2 \%$ em relação ao mesmo mês de 2012, quando já tinha havido crescimento de $10,0 \%$ no consumo sobre o mesmo mês de 2011. O aumento do consumo em novembro de 2013 foi influenciado pela expansão de $3,4 \%$ na base de consumidores, pela aquisição de novos eletrodomésticos, inclusive com incentivo de programas do governo federal, e pelo consequente aumento do consumo médio das residências.

Apesar de todos os investimentos na geração de mais energia precisamos de cabos e fios que conduzam essa energia de forma eficiente e eficaz, assim reduzindo a perda de energia durante o processo que vai desde a sua geração na hidroelétrica até o consumidor final.

Através dos dados mencionados acima podemos verificar uma crescente demanda de energia elétrica em todos os setores da sociedade, e como o Brasil encontra-se com uma capacidade limitada na geração de energia elétrica o governo precisou criar políticas de combate ao desperdício, sendo assim, criaram-se programas de conscientização contra o desperdício elétrico e o horário de verão.

Visando essa problemática de distribuição elétrica que universidades brasileiras buscam uma liga que possua uma boa capacidade de conduzir energia de forma satisfatória e ainda por cima possa ser cada vez mais leve reduzindo assim os custos com torres de transmissão.

Dentro desta realidade, o presente trabalho propõe-se a caracterizar eletromecanicamente a liga $\mathrm{Al}-0,05 \% \mathrm{Cu}-0,4 \% \mathrm{Fe}$ modificada com os teores de $0,15 \% p Z r$ e $0,22 \% p Z r$, objetivando relaciona-lo com a velocidade e taxa de resfriamento, propriedades macroestruturais, eletromecânicas.

\section{2 - MATERIAIS E MÉTODOS}

As ligas foram obtidas por solidificação estática direta, em lingoteira metálica, no Sub-laboratório de Metalografia e Tratamento Térmicos da UFPa. Sua preparação foi realizada inicialmente através de adições de 0,05\%Cu, [0,35-0,45]\%Fe, e em seguida, através da adição de $0,15 \%$ e $0,22 \% Z r$.

Logo após o desmolde, os perfis obtidos no molde em "U" foram usinados para o diâmetro $18,0 \mathrm{~mm}$, sendo posteriormente submetidos ao processo de deformação por laminação a frio que gerou os corpos de provas em forma de fios, nas dimensões de 4,0;3,8; 3,0 e 2,7 mm, dimensões estas que se aproximam das bitolas comerciais produzidas pelas indústrias de fios e cabos para transmissão e distribuição de energia elétrica. Na sequência os perfis foram caracterizados elétrica e mecanicamente como mostra o esquema abaixo

\footnotetext{
* Contribuição técnica ao 69ำ Congresso Anual da ABM - Internacional e ao 14ํㅡㄹ ENEMET - Encontro Nacional de Estudantes de Engenharia Metalúrgica, de Materiais e de Minas, 21 a 25 de julho de 2014, São Paulo, SP, Brasil.
} 


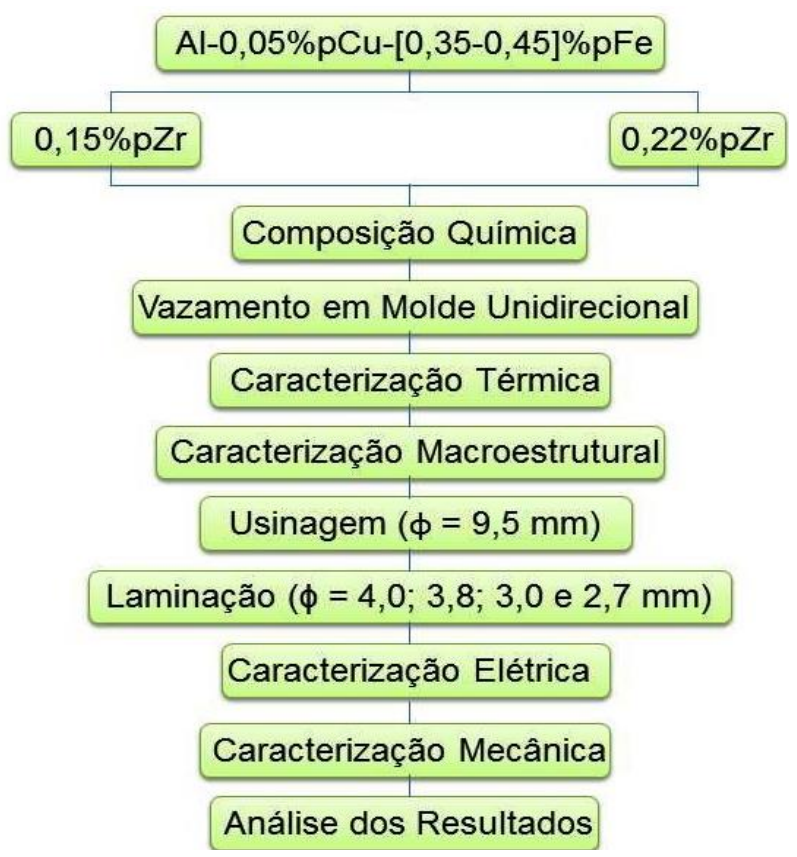

Figura 1. Fluxograma detalhando as operações metalúrgicas e de caracterização para a liga Al-0,05\%Cu-[0,24-0,28]\%Fe-0,7\%Si modicada com Ti e Ni.

Para a preparação das ligas foram utilizadas barras de Al-EC, Cobre e Ferro metálico, barras de liga mãe Al-10\%Zr, que foram cortadas com serra de fitas, pesadas com balança digital e fundidas em forno do tipo mufla, no qual foram executadas todas as operações de fundição.

A composição foi confirmada em espectrômetro óptico de propriedade do sublaboratório de metalografia e tratamento térmico (UFPA). Todo o alumínio utilizado para a obtenção das ligas foi cedido pela empresa parceira no desenvolvimento dos estudos em questão.

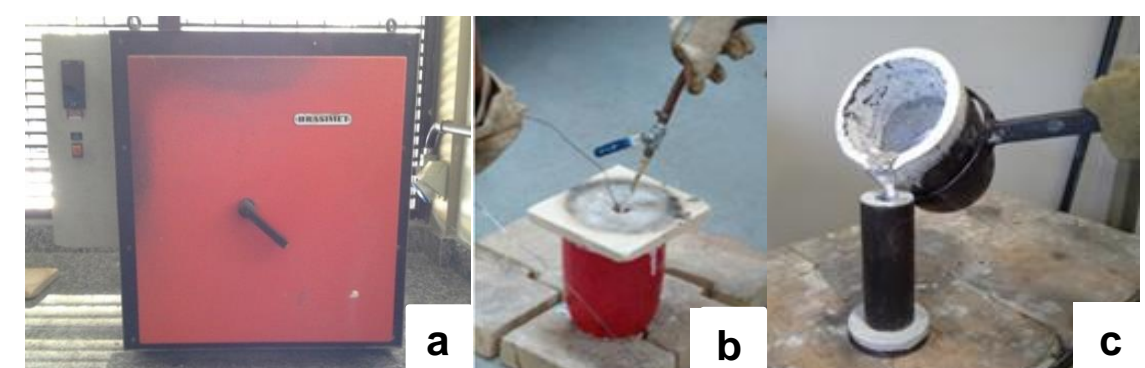

Figura 2. Esquema de preparação e obtenção das ligas tundidas: (a) forno utilizado; (b) injeção de argônio; (c) coleta de amostras para análise química.

Na sequência de imagens ilustrada na Figura 2, tem-se o processo de fundição das ligas nas composições químicas predefinidas no forno (Figura 2a), seguida de injeção de argônio (Figura 2b), e vazamento para obter-se as amostras para a análise química (Figura 2c).

\subsection{Composição Química}

Com a amostra testemunho, medindo aproximadamente 2 pol $(5,1 \mathrm{~cm})$, Figura $3(\mathrm{a})$, faz-se a análise química através do espectrômetro óptico, Figura 3(b), onde os

* Contribuição técnica ao 69 Congresso Anual da ABM - Internacional e ao 14ํㅡㄹ ENEMET - Encontro Nacional de Estudantes de Engenharia Metalúrgica, de Materiais e de Minas, 21 a 25 de julho de 2014, São Paulo, SP, Brasil. 
resultados são obtidos a partir da média de no mínimo três leituras da composição química da amostra, Figura 3(c).

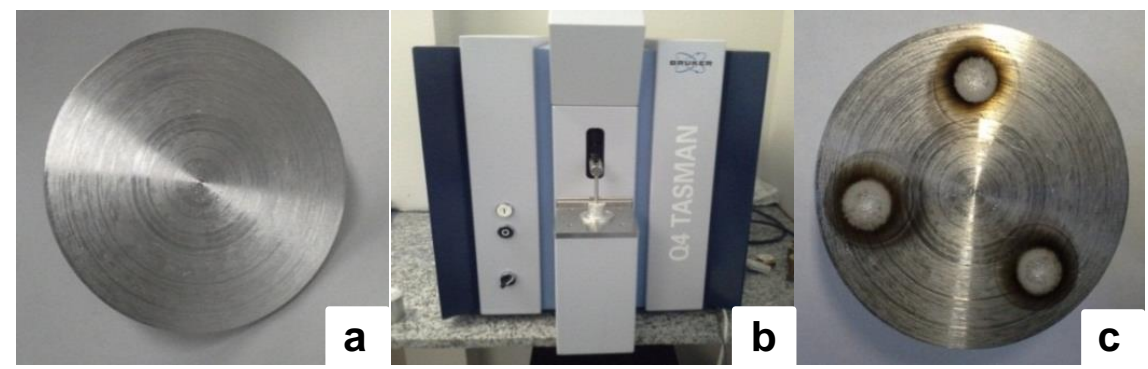

Figura 3 - Amostra testemunho (a); Espectrômetro de massa (b) e (c) amostra após a análise química.

\subsection{Dimensionamento do Molde de Solidificação Unidirecional Horizontal}

Para as dimensões do molde, baseou-se através do trabalho de Quaresma [1]. E para sua montagem, utilizou-se um molde de geometria regular com as dimensões

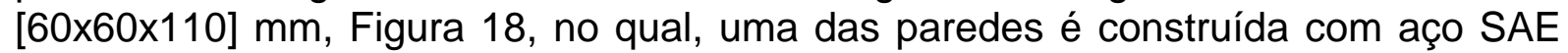

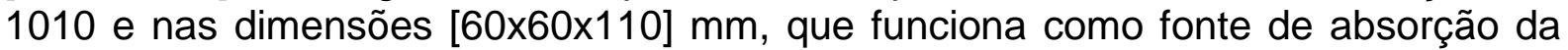
carga térmica liberada pelo metal líquido. O molde possui um furo posicionado a 3,0 $\mathrm{mm}$ da interface metal/molde. E, a partir do topo da parede superior do molde, é possível posicionar os termopares para medir a temperatura liquidus.

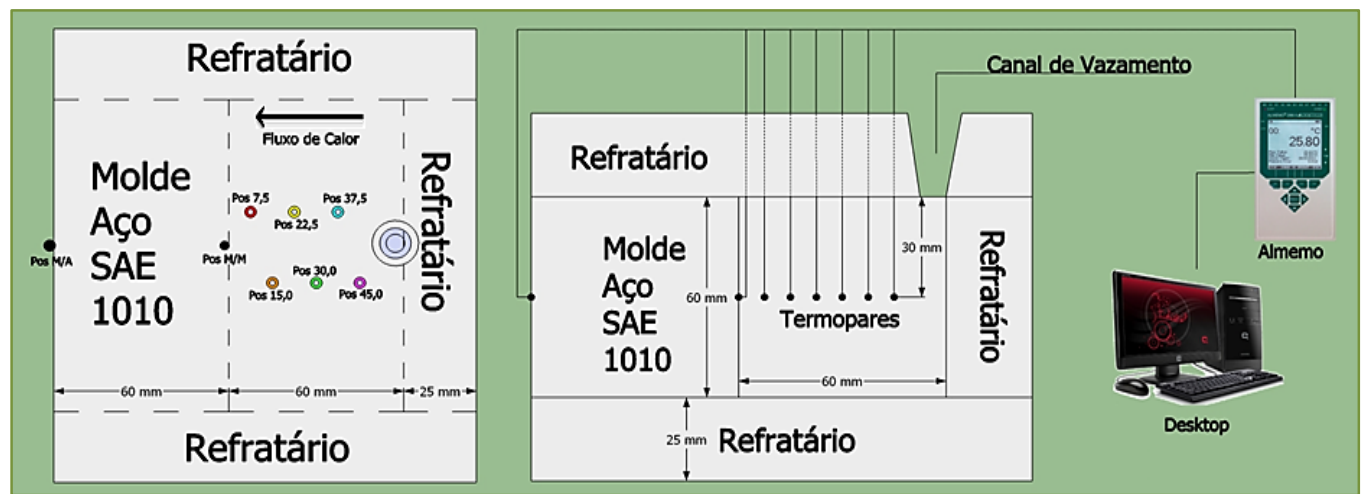

Figura 4 - Esquemático do aparato de solidificação unidirecional horizontal, com os posicionamentos dos termopares e registro de dados.

\subsection{Preparação dos Corpos de Prova}

Os corpos de prova passaram por processos de usinagem Figura 21(a), para o diâmetro de $9,5 \mathrm{~mm}$. Posteriormente passaram por conformação mecânica a frio (laminação), Figura 21(b), para os diâmetros $\Phi(4.0,3.8,3.0) \mathrm{mm}$.

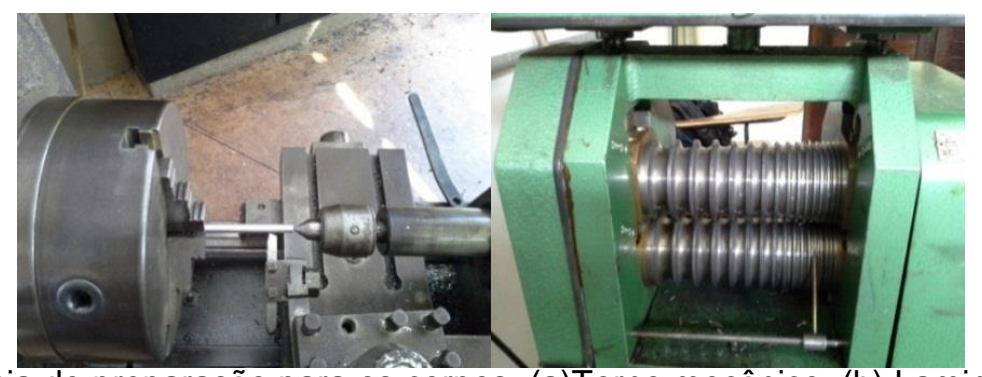

Figura 51 - Sequência de preparação para os corpos: (a)Torno mecânico; (b) Laminador elétrico duo reversível. Nacional de Estudantes de Engenharia Metalúrgica, de Materiais e de Minas, 21 a 25 de julho de 2014, São Paulo, SP, Brasil. 


\subsection{Caracterização Elétrica}

Após a deformação a frio das ligas e a obtenção dos diâmetros desejados no estudo, os corpos de prova foram submetidos aos ensaios de caracterização elétrica e mecânico. No ensaio elétrico o objetivo é avaliar a resistividade dos corpos de prova, com o auxílio de um multiohmímetro MEGABRÁS (ponte de kelvin), modelo MPK-2000. O teste de resistividade são conforme a norma NBR 6815 [2].

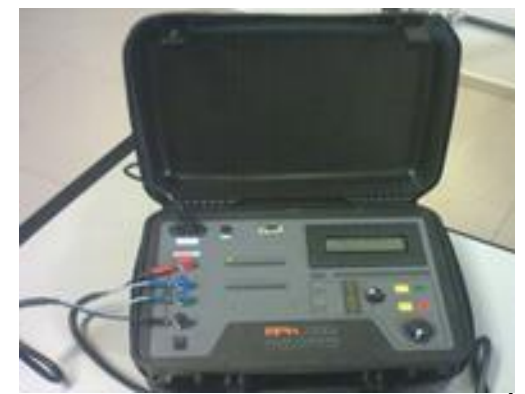

Figura 6 - Multiohmímetro (ponte de kelvin) MEGABRÁS modelo MPK-2000.

\subsection{Caracterização Mecânica}

O ensaio mecânico foi realizado em uma máquina de ensaio de tração KRATOS, modelo IKCL1-USB, acoplada a um micro computador com sistema de aquisição de dados que facilita a coleta das informações. O teste de tração foi realizado segundo a norma para cabos elétricos NBR 6810 [3] e, portanto, executados em três amostras com $20 \mathrm{~cm}$ de comprimento para cada diâmetro ou tratamento térmico produzido ao longo do trabalho em cada etapa.

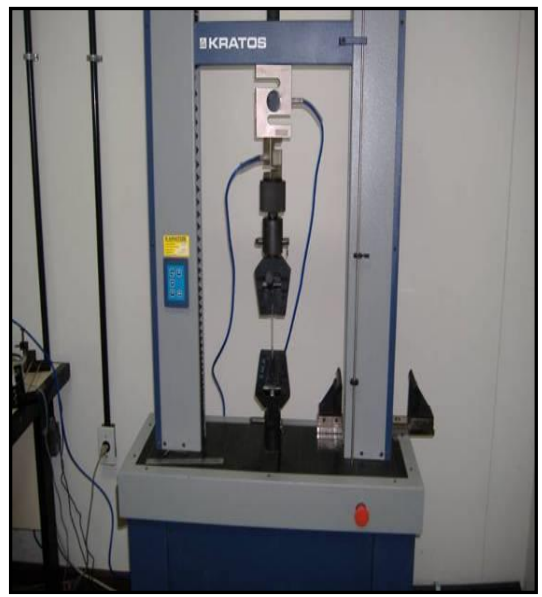

Figura 7 - KRATOS, modelo IKCL1-USB

* Contribuição técnica ao 69 Congresso Anual da ABM - Internacional e ao 14ํㅡㄹ ENEMET - Encontro Nacional de Estudantes de Engenharia Metalúrgica, de Materiais e de Minas, 21 a 25 de julho de 2014, São Paulo, SP, Brasil. 


\section{RESULTADOS}

A Tabela 1 mostra os resultados da análise da composição química para as ligas Al$0,05 \% \mathrm{Cu}-[0,35-0,45] \% \mathrm{Fe}$ modificada com $0,15 \% \mathrm{Zr}$ e $0,22 \% \mathrm{Zr}$. Esta leitura foi obtida a partir de análise em espectrômetro óptico de massa.

Tabela 1. Composição química da liga de Alumínio modificada com Zircônio.

\begin{tabular}{cccc}
\hline & \multicolumn{3}{c}{ Elementos de Liga (\%p) } \\
\cline { 2 - 4 } Liga & Cobre & Ferro & Zircônio \\
\hline Al-0,05\%pCu-[0,35-0,45]\%pFe-0,15\%pZr & 0,045 & 0,397 & 0,148 \\
$\mathrm{Al}-0,05 \% \mathrm{pCu}-[0,35-0,45] \% \mathrm{pFe}-0,22 \% \mathrm{pZr}$ & 0,042 & 0,399 & 0,216 \\
\hline
\end{tabular}

\subsection{Caracterização Térmica}

As Figuras 8(a) e 8(b), abaixo, apresentam as curvas de resfriamento para as ligas com $0,15 \%$ e $0,22 \%$ de $\mathrm{Zr}$ respectivamente. Estas curvas foram obtidas experimentalmente através do vazamento em molde unidirecional horizontal, através de [6] seis termopares posicionados dentro da câmara de vazamento e conectados ao registrador térmico de maneira a permitir a obtenção do histórico térmico da solidificação.

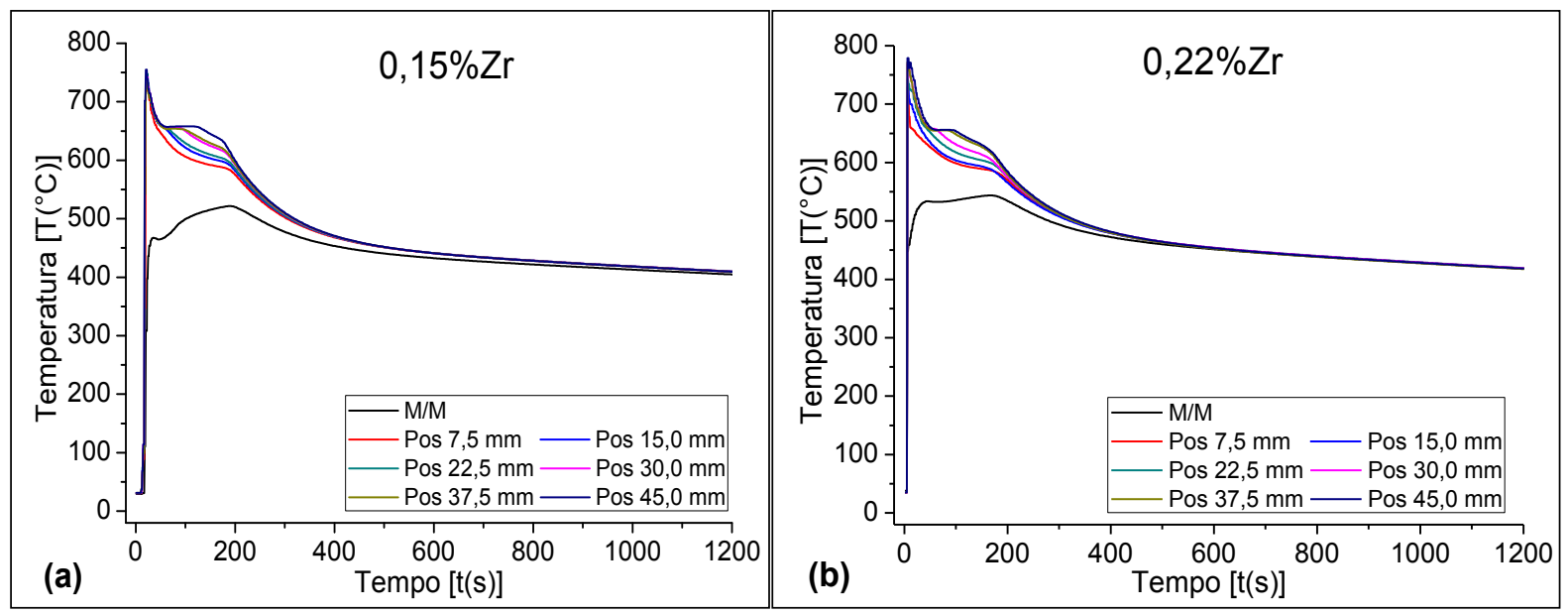

Figura 8 - Curvas de resfriamento das ligas modificada com a) 0,15\%pZr b) 0,22\%pZr.

Após obterem-se as curvas de resfriamento para cada termopar posicionado na câmara de vazamento, determinam-se ao momento o qual esta isoterma liquidus passa por cada um eles. A Tabela 2 apresenta os tempos de passagem.

Tabela 2. Posição $X$ tempo

\begin{tabular}{cccccccc}
\hline \multicolumn{2}{c}{ Posição (mm) } & 7,5 & 15 & 22,5 & 30,0 & 37,5 & 45 \\
\hline $0,15 \% \mathrm{Zr}$ & Tempo (s) & 10 & 33 & 48 & 59 & 74 & 102 \\
$0,22 \% \mathrm{Zr}$ & Tempo (s) & 10 & 25 & 38 & 56 & 60 & 86 \\
\hline
\end{tabular}

Com estes tempo pode-se plotar os gráficos de posição em função do tempo Os resultados são apresentados graficamente na Figura 9(a), de onde, a partir da utilização de um modelo de regressão não-linear do tipo potência, são obtidas equações do tipo Posição x Tempo mostradas no gráfico. Tais equações, quando diferenciadas permitem obter experimentalmente da equação da Velocidade de

* Contribuição técnica ao 69 Congresso Anual da ABM - Internacional e ao 14ํㅡㄹ ENEMET - Encontro Nacional de Estudantes de Engenharia Metalúrgica, de Materiais e de Minas, 21 a 25 de julho de 2014, São Paulo, SP, Brasil. 


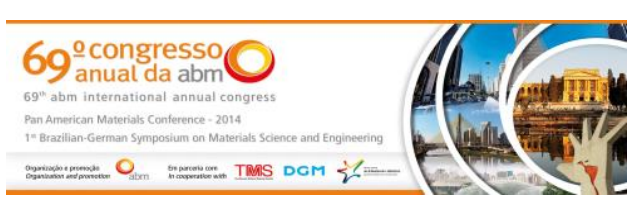

Solidificação em função do tempo, como mostra a figura 9 (b), onde também é retirado através do mesmo método de regressão não-linear as equações das velocidades em função do tempo.

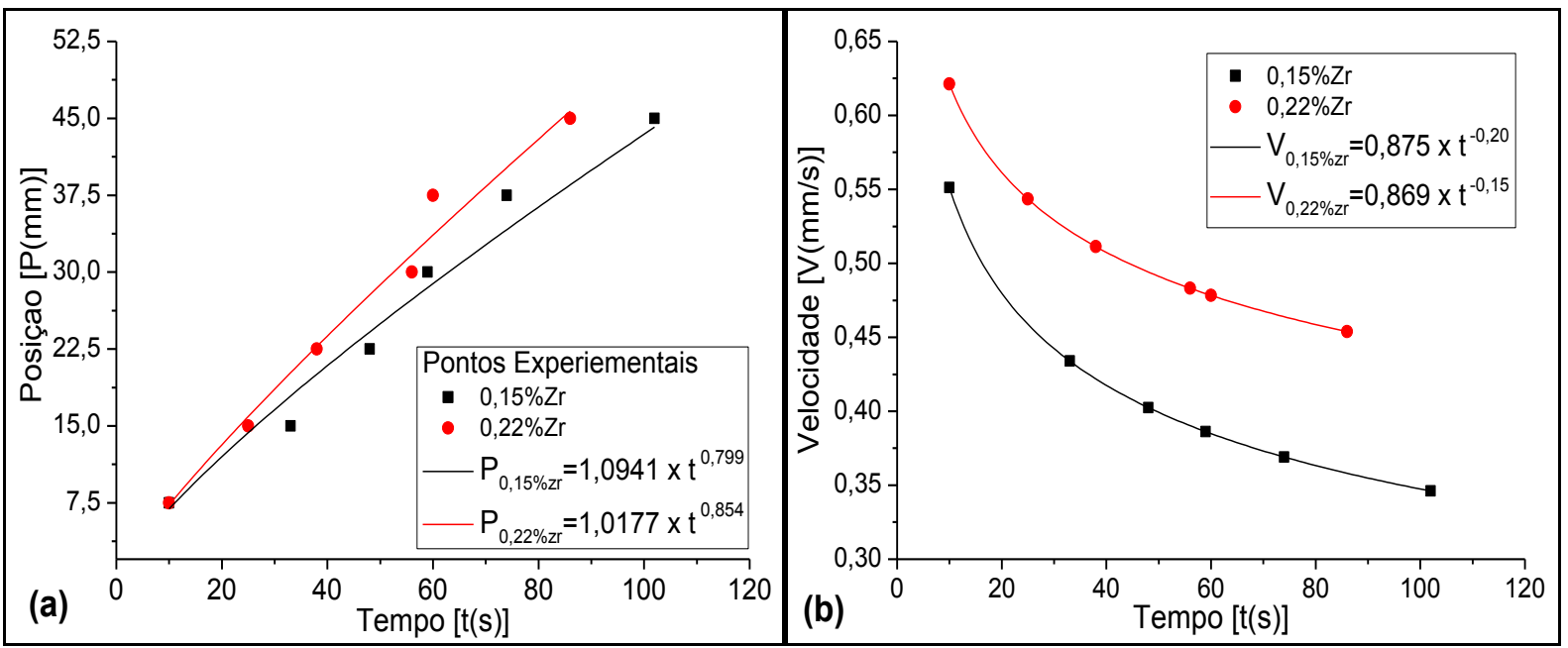

Figura 9 - Gráfico a) Posição x Tempo b) Velocidade x Tempo.

Esta equação (posição x tempo), após manipulação algébrica, pode ser expressa em função da Posição, conforme pode ser observado na figura 10.

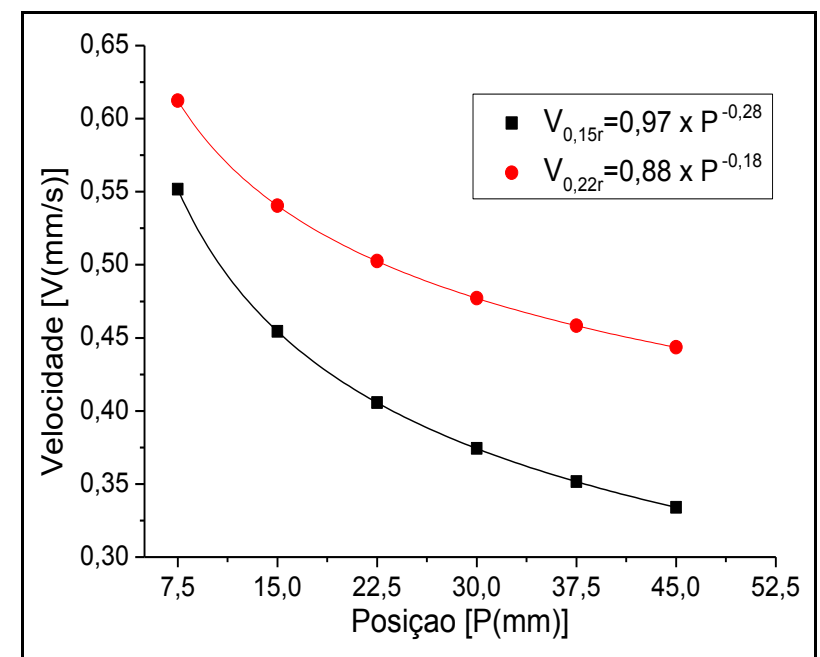

Figura 10 - Gráfico Velocidade x Posição.

As taxas de resfriamento foram determinadas baseando-se em um método descrito por Okamoto e Kishitake (1975) onde a taxa de resfriamento é obtida experimentalmente a partir do Método Numérico de Diferenças Finitas que se apoia na referência da temperatura liquidus $(T L)$ contida nas curvas de resfriamento para cada posição dos termopares. É calculada pelo módulo da razão entre os intervalos de temperatura e tempo obtidos antes e depois da passagem da isoterma liquidus para cada termopar. Os resultados destes cálculos estão apresentados na Tabela 3.

Tabela 3. Tempos e temperaturas para determinar a taxa experimental em função da posição.

\begin{tabular}{ccccccc}
\hline \multicolumn{7}{c}{ Taxa experimental X posição } \\
\hline Posição & 7,5 & 15 & 22,5 & 30,0 & 37,5 & 45 \\
$0,15 \% Z r$ & 3,03 & 0,71 & 0,37 & 0,12 & 0,09 & 0,06 \\
$0,22 \% Z r$ & 3,41 & 1,65 & 1,20 & 0,66 & 0,53 & 0,21 \\
\hline
\end{tabular}

* Contribuição técnica ao 69 Congresso Anual da ABM - Internacional e ao 14ํㅡㄹ ENEMET - Encontro Nacional de Estudantes de Engenharia Metalúrgica, de Materiais e de Minas, 21 a 25 de julho de 2014, São Paulo, SP, Brasil. 


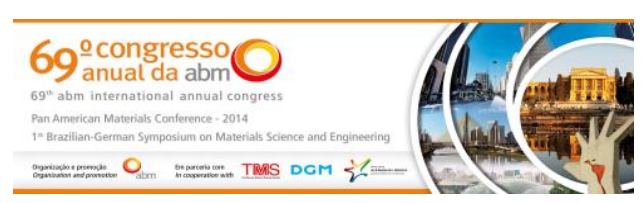

Analogamente ao observado nas velocidades de solidificação, nos pontos mais próximos da fonte extratora de calor, observam-se taxas de resfriamento maiores, que vão diminuindo ao longo do comprimento do lingote. Esta tendência é apresentada na Figura 11.

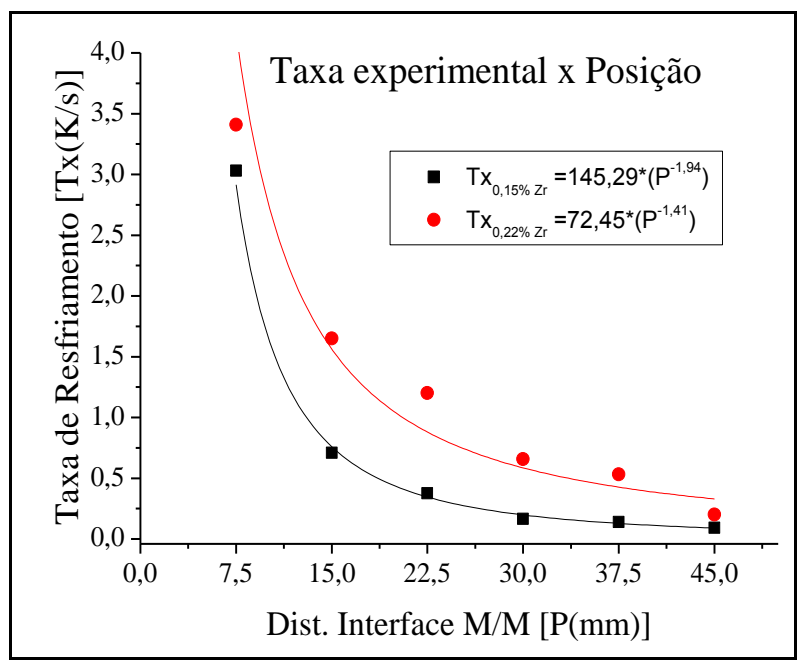

Figura 11 - Gráfico Taxa experimental x Posição.

\subsection{Caracterização Macroestrutural}

A seguir, na Figura 12, pode ser observado a evolução das estruturas produzidas para a liga com os teores de $\mathrm{Zr}$. A estrutura das ligas foi revelada por meio de ataque com solução química "Poulton" de composição [12ml HCl (conc.), $6 \mathrm{ml}$ HNO3 (conc.), $1 \mathrm{ml} \mathrm{HF} \mathrm{(48 \% ),} 1 \mathrm{ml} \mathrm{H} 2 \mathrm{O}]$.
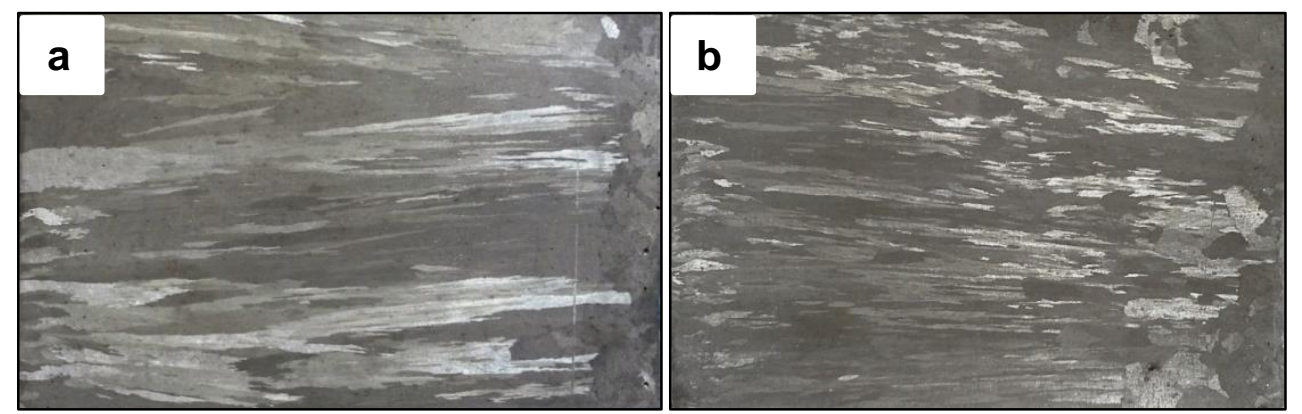

Figura 12 - Macrografias das ligas modificadas com os teores (a) $0,15 \%$ pZr (b) $0,22 \% p Z r$

Segundo Santos [4], o elemento Zr não apresenta característica de refino de grão ate 0 teor de $0,2 \%$. Entretanto mesmo que no presente trabalho esteja trabalhando com o teor de $0,22 \%$, não ouve refino de grão. O que nos leva a considerar que a capacidade do refino de grão do Zr também esta relacionando com a presença dos outros elementos de liga, onde o ferro neste trabalho esta com maior teor do que no trabalho de Santos [4], e não há a presença do Si.

Em ambas as figuras nota-se presença de grãos coquilhados, formados junto às paredes do molde, sendo resultado de um primeiro contato do metal líquido com o molde ainda frio durante o vazamento. Segundo Garcia [5], altas taxas de resfriamento provocarão uma rápida diminuição local da temperatura, favorecendo uma nucleação intensa de grãos. Tal redução de temperatura ocasionará um superresfriamento térmico, resultando em grãos cristalinos de forma e tamanho pequeno, Nacional de Estudantes de Engenharia Metalúrgica, de Materiais e de Minas, 21 a 25 de julho de 2014, São Paulo, SP, Brasil. 


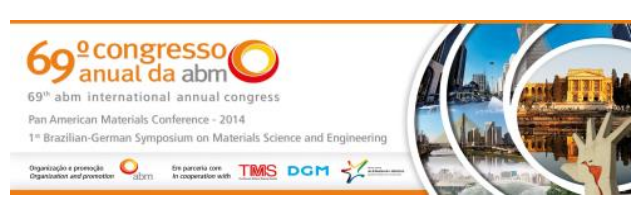

quase sempre uniformes, cujas orientações são aleatórias, formando uma fina camada junto às paredes do molde.

\subsection{Caracterização Elétrica}

Para liga de alumínio a condutibilidade medida em \% IACS em condutores a $20{ }^{\circ} \mathrm{C}$ está na faixa de 52,50 a 61,5\% IACS. A Figura 13 mostra que a condutibilidade dos corpos de prova da liga $0,22 \% Z r$. Esta foi à liga selecionada para ser realizada a caracterização elétrica. A escolha foi feita com base nos resultados de caracterização térmica e macroestrutural, onde apresentou maiores velocidades e taxas de resfriamento e uma nucleação mais intensa dos grãos.

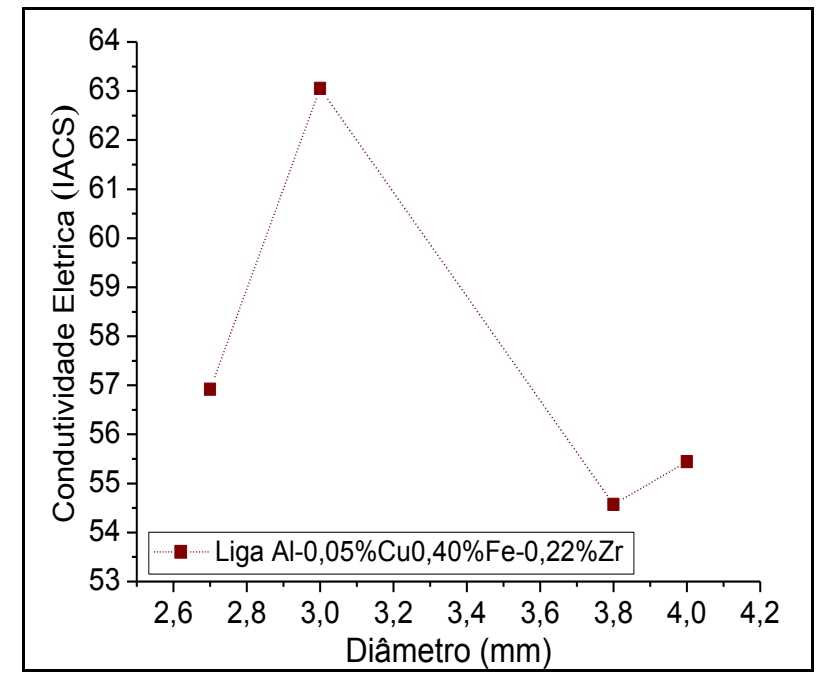

Figura 13 - Gráfico Condutividade Elétrica x Diâmetro.

Pela Figura 13, nota-se o ganho considerável da condutividade elétrica para o diâmetro de 3,0mm. Esse é o um comportamento característico do fenômeno de recuperação dinâmica [6], em que após a deformação a frio o material se recupera e reduz a resistência elétrica do material, aumentando sua condutividade elétrica. Um comportamento característico observado também esta relacionado com os diâmetros 2,7 e 3,8 mm, que apresentam menores resultados na condutividade em relação ao diâmetro de 3,0 e 4,0mm. Esse fato pode ser explicado, pois o quando se inicia a deformação a tensão que é gerada pra deformar o material é menor de uma escala de 0,2 , no caso de 4,0 para $3,8 \mathrm{~mm}$, do que na escala de 0,8 , no caso de 3,8 para 3,0, sendo que a carga térmica gerada não é suficiente para realizar a recuperação no material, deixando o material apenas encruado ou apenas inicia a recuperação, o que não é suficiente para rearranjar as discordâncias e diminuir o aumento da resistência elétrica provocado pelo encruamento.

\subsection{Caracterização Mecânica}

Os valores de resistência mecânica das ligas estão representados na Figura 14 para a liga $0,22 \% Z r$ escolhida assim como no caso da caracterização elétrica. Também foi feito um gráfico representando o alongamento para a mesma liga após o ensaio de tração.

\footnotetext{
* Contribuição técnica ao 69 Congresso Anual da ABM - Internacional e ao 14ํㅡㄹ ENEMET - Encontro Nacional de Estudantes de Engenharia Metalúrgica, de Materiais e de Minas, 21 a 25 de julho de 2014, São Paulo, SP, Brasil.
} 


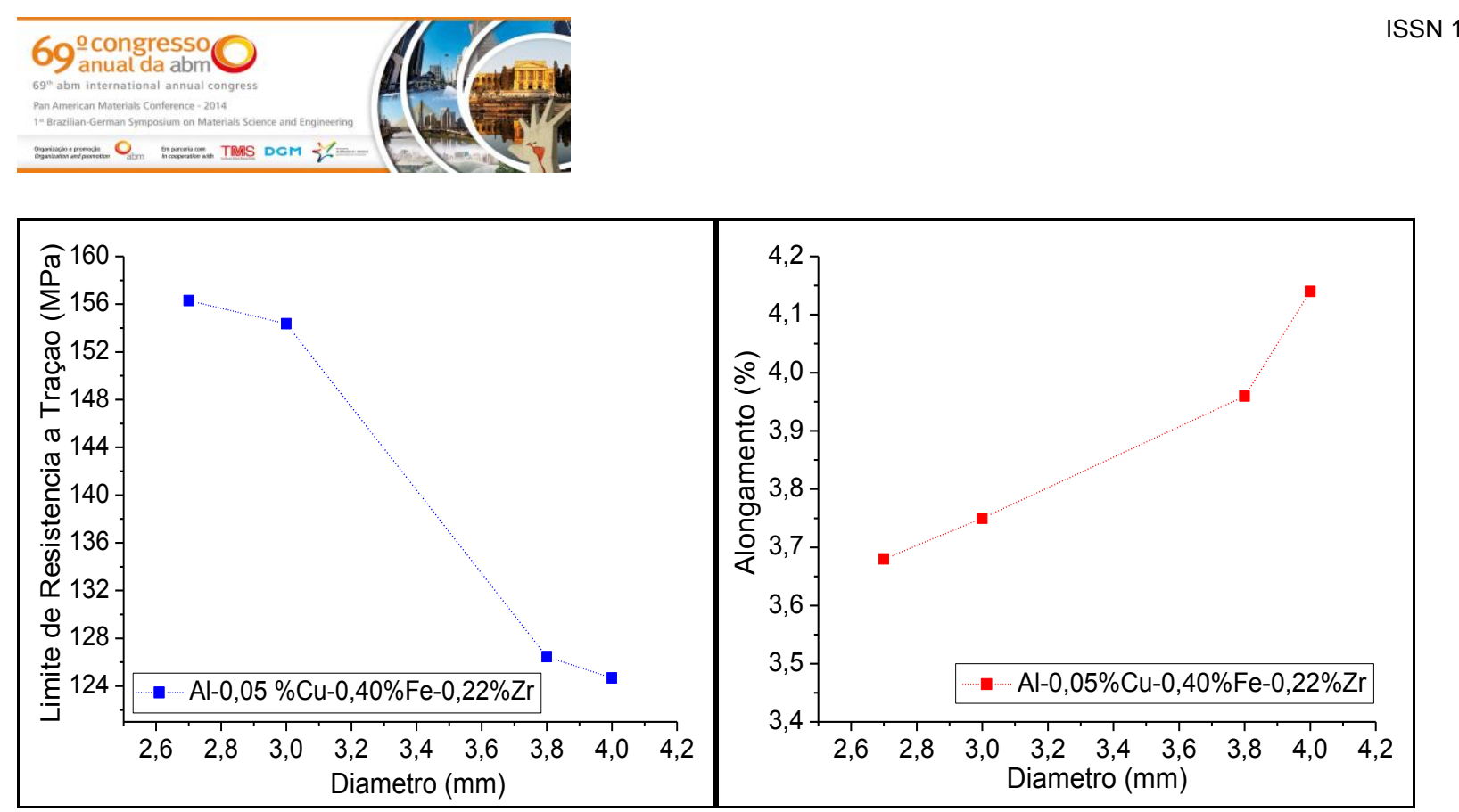

Figura 14 - Gráfico a) Limite de Resistencia a Tração x Diâmetro b) Alongamento x Diâmetro.

Observa-se no gráfico da resistência a tração, que o melhor resultado esta para o diâmetro de $2,7 \mathrm{~mm}$. E ele vai caindo à medida que o diâmetro vai aumentando. Isso ocorre porque o corpo de prova vai sofrendo deformação a frio desde o diâmetro de $9,5 \mathrm{~mm}$, e nesse processo de deformação ele vai encruando e melhorando suas propriedades mecânicas, nesse caso o LRT. Esse melhoramento também pode ser comprovado que a recuperação acontece sem prejudica o LRT. E este é o comportamento característico do fenômeno de recuperação dinâmica [6].

Já para o alongamento o que ocorre é o inverso do limite de resistência, ou seja, ocorre uma diminuição da capacidade do material alongar. E esse fenômeno ocorre no encruamento. E só pode ser desfeito se o material passar por um processo de recristalização.

\section{CONCLUSÃO}

Após a análise dos resultados, observou-se que a liga com $0,22 \% \mathrm{Zr}$ apresentou maiores velocidades de resfriamento e taxa de resfriamento. Na macroestrutura nota-se uma maior presença de grãos equiaxais na liga com $0,15 \% \mathrm{Zr}$. A liga com $0,22 \% Z r$ apesenta grão mais delgados, essas estruturas de grãos das ligas podem ser relacionadas com as taxas de resfriamento das ligas.

$O$ resultado de condutividade elétrica mostra que o diâmetro de 3,0 $\mathrm{mm}$ apesentou melhor resultado, isso se deve ao fenômeno da recuperação dinâmica. E para o limite de resistência a tração o diâmetro de $2,7 \mathrm{~mm}$ apresentou melhor resultado, 0 que estar relacionado com o fenômeno do encruamento que aumenta as propriedades mecânicas do material. E para o alongamento, observou-se um decréscimo no seu valor à medida que o diâmetro diminuiu, isso porque a deformação é maior, e maior será o encruamento, que diminui a capacidade do material de alongar.

\section{REFERÊNCIAS}

1 Quaresma JMV. Correlações entre condições de solidificação, microestrutura e resistência mecânica, Campinas: 1999. 323f. Tese (Doutorado em Engenharia Mecânica) - Faculdade de Engenharia Mecânica/Universidade de Campinas, Campinas, 1999.

\footnotetext{
* Contribuição técnica ao 69 Congresso Anual da ABM - Internacional e ao 14ํㅡㄹ ENEMET - Encontro Nacional de Estudantes de Engenharia Metalúrgica, de Materiais e de Minas, 21 a 25 de julho de 2014, São Paulo, SP, Brasil.
} 
2 Associação Brasileira de Normas Técnicas (ABNT NBR 6815). Fios e cabos elétricos Ensaio de determinação da resistividade em componentes metálicos. Rio de Janeiro, ago. 1981.

3 Associação Brasileira de Normas Técnicas (ABNT NBR 6810). Fios e cabos elétricos Tração à ruptura em componentes metálicos. Rio de Janeiro, ago. 1981.

4 Santos W. L. R.; Efeito de Teores de Zr Sobre as Propriedades Mecânicas e Elétricas de Ligas Al-Ec-Si Aplicadas na Elaboração de Ligas para Tx e Dx de Energia Eletrica, Belém 2010.105f. Dissertação (Mestrado em Materiais e Processos de Fabricação) Programa de Pós-Graduação em Engenharia Mecânica, Instituto de Tecnologia, Universidade Federal do Pará, Belém, 2010.

5 Garcia A. Solidificação: Fundamentos e aplicações. Campinas: UNICAMP, 2001.

6 Padilha AF, Siciliano JrF. Encruamento, recristalização, crescimento de grão e textura. São Paulo: ABM, 1995. 123 p. 